\title{
Effects of Breast Feeding Practice in Respiratory Syncytial Virus Positive Bronchiolitis in Early Infancy
}

\author{
Nazrul Quader Shikder ${ }^{1 *}$ \\ A.J.M Sadeque ${ }^{1}$ \\ Rabeya Begum² \\ Mizanur Rahman ${ }^{3}$ \\ ${ }^{1}$ Department of Paediatric \\ Institute of Applied Health Sciences (IAHS) \\ Chattogram, Bangladesh. \\ ${ }^{2}$ Department of Mother and Child Health \\ Rowzan Upazila Health Complex \\ Chattogram, Bangladesh. \\ ${ }^{3}$ Department of Paediatric \\ Chittagong Medical College \\ Chattogram, Bangladesh.
}

*Correspondence to:

Dr. Nazrul Quader Shikder

Assistant Professor

Department of Paediatric

Institute of Applied Health Sciences (IAHS)

Chattogram, Bangladesh.

Mobile : +8801926825372

Email :nazrulshikder@gmail.com

Date of Submission : $\quad 15.06 .2020$

Date of Acceptance : $\quad 25.08 .2020$

www.banglajol.info/index.php/CMOSHMCJ

\begin{abstract}
Background: Bronchiolitis is a common respiratory illness. It can be diagnosed clinically, as well as by a few costly laboratory tests. It has no specific treatment except supportive measures. Respiratory Syncytial Virus (RSV) related Bronchiolitis carries near about 1\% mortality and involve an economical load. The objective of this study was to compare effecte of breast feeding practice in relation with RSV positivity among bronchiolitis in early infancy.
\end{abstract}

Material and methods: This case control study is designed to evaluate the effects of breast feeding practice among the RSV positive bronchiolitis patients during a period of 1 year. A total 40 patients of bronchiolitis were evaluated who have exclusive breast feeding and non exclusive breast feeding. RSV positivity were analyzed among both groups and compared. Patients were selected after taking consent from guardians, patient diagnosed as bronchiolitis, age 2 month to 2 year and all tests are done in Department of Microbiology, Chittagong Medical College Hospital $(\mathrm{CMCH})$. Results were evaluated to find out the effects of breast feeding practice in relation with $R S V$ positivity bronchiolitis in early infancy.

Results: Among all 40 patients, male was 25(62.5\%) and female was 15(37.5\%). Male to female ratio was 1.67:1. Majority of guardians were workers 18(45\%), service holder 11(27.5\%) and businessman 10(25\%). Regarding socioeconomic conditions of the parents where 26(65\%) were poor and 14(35\%) were rich. Twenty five (62.5\%) were from rural areas and 15(37.5\%) were from urban locality. Different history related with risk factors of bronchiolitis were evaluated where 11(27.5\%) patients had H/O prematurity, 10(25\%) had parental smoking history, nonexclusive breast feeding 13(32.5\%) and supplemental feeding had 13(32.5\%) cases. Regarding pattern of breast feeding 27(67.5\%) were given exclusive breast feeding and non exclusive breast feeding were 13 (32.5\%) of which only formula milk was given to $1(2.5 \%)$ case and cow's milk and formula milk jointly was given in $12(30.0 \%)$ cases. Findings of clinical histories revealed that all 40 patients had cough, respiratory distress and excessive cry, cyanosis was present in 39(97.5\%) cases and cent percent patients had chest in drawing and all of were categorized as severe bronchiolitis. Regarding RSV testing 15 (37.5\%) cases were found to having RSV positive and remainder portion were negative. Significant association was found regarding RSV status and exclusive breast feeding where more negativity was found among those who were exclusively breast feed.

Conclusion: There is significant association between RSV positivity bronchiolitis andnon-exclusively breast feed children.

Key words: Breast feeding; Effect; RSV positivity in early infancy.

\section{INTRODUCTION}

Bronchiolitis is the most significant respiratory illness of infants and young children. It is an acute inflammatory illness of children that occurs in the first 2 years of age 
and is characterized by coryzal symptoms followed by rapid onset of fever, wheeze, tachypnea, chest recession and crepitation, with radiological evidence of hyperinflation.

Seasonality of bronchiolitis caused by Respiratory Syncytial Virus (RSV) is striking and predictable. The incidence peaks during winter and early spring and reaches near zero in late summer and autumn in both hemispheres, in tropical climates, occurrences of RSV bronchiolitis tends to coincide with rainy season. Bronchiolitis caused by other agents occur throughout the year. The age for peak incidence of RSV bronchiolitis is between 2 and 6 months, approximately $80 \%$ of all cases occur during the first year of life. Two sub types (A and B) of RSV exist sub type A is more common cause of bronchiolitis and is associated with more severe disease. The age for peak incidence in urban areas may be earlier from 2 to 3 months of age. Bronchiolitis is seen in children as old as 2 years in more remote localities and in areas where risk of exposure is reduced ${ }^{1}$.

The burden of disease is significant. Around $70 \%$ of all infants will be infected with RSV in their first year of life and $22 \%$ develop symptomatic disease. Since RSV is associated with only $75 \%$ of bronchiolitis cases, it may be estimated that around a third of all infants will develop bronchiolitis (From all viruses) in their first year of life ${ }^{2}$.

For Scotland this translates to approximately 15,000 infants. Around $3 \%$ of all infants younger than one year are admitted to hospital with bronchiolitis ${ }^{3}$. Based on Scottish morbidity recording for the years 2001 to 2003 a mean of 1,976 children per year (Aged up to 12 months) were admitted to hospital with bronchiolitis as the principal diagnosis ${ }^{4}$.

Younger infants have a higher risk of hospital admission with bronchiolitis than older infants ${ }^{5}$. Infants born prematurely have a modestly higher rate of RSV-associated hospitalisation compared with full-term healthy babies ${ }^{6}$.

To compare effect of breast feeding practice in relation with RSV positivity among bronchiolitis in early infancy.

\section{MATERIALS AND METHODS}

This case control study is designed to evaluate the effects of breast feeding practice among the RSV positive bronchiolitis patients. A total 40 patients of bronchiolitis were evaluated who have exclusive breast feeding and non exclusive breast feeding. RSV positivity were analyzed among both groups and compared.

\section{Inclusion criteria:}

i. Patients diagnosed as bronchiolitis

ii. Age after 2 month to 2 year.

Exclusion criteria:

i. Patients with known congenital heart disease

ii. Guardian of the subject who will not provide written consent to participate in the study.
All tests were done in Department of Microbiology $\mathrm{CMCH}$, Results were evaluated to find out the effects of breast feeding practice in relation with RSV positivity of bronchiolitis in early infancy.

\section{RESULTS}

Table I : Gender distribution.

\begin{tabular}{lrrrcrr} 
& Case & Control & Total & Percent (\%) & OR & p \\
Male & 11 & 14 & 25 & 62.5 & 1.45 & .042 \\
Female & 8 & 7 & 15 & 37.5 & & \\
Total & 19 & 21 & 40 & 100.0 & & \\
\hline
\end{tabular}

Table I showing gender distribution of bronchiolitis patients where male was $25(62.5 \%)$ and female was $15(37.5 \%)$. Male to female ratio was $1.65: 1$

Table II : Breast feeding history.

\begin{tabular}{lcc} 
& Frequency & Percent (\%) \\
Exclusive breast feeding & 27 & 67.5 \\
Non-exclusive breast feeding & 13 & 32.5 \\
Total & 40 & 100.0 \\
\hline
\end{tabular}

Table II showing pattern of breast feeding where $27(67.5 \%)$ were given exclusive breast feeding and 13(32.5\%) were given non-exclusive breast feeding cases.

Table III : RSV testing.

\begin{tabular}{lcc} 
& Frequency & Percent (\%) \\
RSV positive & 15 & 37.5 \\
RSV negative & 25 & 62.5 \\
Total & 40 & 100.0 \\
\hline
\end{tabular}

Table III showing 15(37.5\%) cases were found to having RSV positive.

Table IV : Association between RSV status and exclusive breast feeding.

\begin{tabular}{|c|c|c|c|}
\hline Breast feeding & RSV Positivity & Total & $\mathrm{OR}(\mathrm{CI})$ \\
\hline status & $\begin{array}{ll}\text { RSV } & \text { RSV } \\
\text { positive } & \text { negative }\end{array}$ & & \\
\hline
\end{tabular}

\begin{tabular}{|c|c|c|c|c|c|c|c|}
\hline $\begin{array}{l}\text { Exclusive } \\
\text { breast } \\
\text { feeding }\end{array}$ & Yes & $\begin{array}{l}\text { Count } \\
\% \text { within RSV } \\
\text { positivity }\end{array}$ & $40.0 \%$ & $\begin{array}{r}21 \\
84.0 \%\end{array}$ & $\begin{array}{r}27 \\
67.5 \%\end{array}$ & & \\
\hline & No & $\begin{array}{l}\text { Count } \\
\% \text { within RSV } \\
\text { positivity }\end{array}$ & $60.0 \%$ & 4 & $\begin{array}{r}13 \\
32.5 \%\end{array}$ & $\begin{array}{r}0.127 \\
(0.029- \\
562)\end{array}$ & 0.004 \\
\hline Total & & $\begin{array}{l}\text { Count } \\
\% \text { within RSV } \\
\text { positivity }\end{array}$ & $100.0 \%$ & $100.0 \%$ & $100.0 \%$ & & \\
\hline
\end{tabular}

Table IV showing significant association was found regarding RSV status and exclusive breast feeding where more negativity was found among those who were exclusively breast fed (OR$0.127, \mathrm{p}=0.004)$. 


\section{DISCUSSION}

This study was conducted in the Department of Paediatrics $\mathrm{CMCH}$ during a period of one year among 40 patients of bronchiolitis. It was a case control study. Patients of bronchiolitis were recruited from patients admitting in the wards and severity and arterial blood gases were assessed in all cases.

Male sex is known to be a risk factor for severe RSV, LRTI (Lower Respiratory Tract Infection). The reason therefore seems to be of anatomic nature that boy have shorter and narrower airways and are more likely to develop bronchial obstruction in case of RSV infection ${ }^{7}$. In the present study male was $25(62.5 \%)$ and female was $15(37.5 \%)$. Male to female ratio was $1.67: 1$. In this study male patients were more than the female. In a study Simos found that risk ratio of boys to girls being $1.425: 1^{8}$. Another study done in BSMMU Bangladesh shows that bronchiolitis was more predominant in male children (Male $68 \% \mathrm{~V}$ female $32 \%$ ). So all these study support our study ${ }^{9}$.

Regarding pattern of breast feeding where, 27(67.5\%) were given exclusive breast feeding of which only formula milk was given to1(2.5\%) case and cow's milk with formula milk was given in $12(30.0 \%)$ cases.

In our country cow's milk is widely available and people used to feed their babies with cow's milk and due to high cost formula milk is less commonly used. The role of breast feeding is preventing RSV disease and hospitalization for RSV is undisputed. However data about the specific protective effect of breast feeding on RSV infection are conflicting. The reason for its protective effect is attributed to RSV-IgA and Lactoferrin in the breast milk as well as to the fact that breast milk promotes maturation probably through the influence of prolactin. Some studies indicate that the absence of breast-feeding in combination with other risk factors like crowding, passive smoke exposure or low socioeconomic status significantly increases the risk for development of RSV, LRTI (Lower Respiratory Tract Infection) ${ }^{10}$.

Among all 40 case, 15(37.5\%) were found to having RSV positive and significant association was found regarding RSV status and exclusive breast feeding where more negativity was found among those who were non exclusively breast feed (OR0.127, $\mathrm{p}=0.004$ ). In different studies, a strong association was evident for the protection of exclusive or predominant breastfeeding against respiratory morbidity as opposed to the introduction of formula milk ${ }^{11-15}$. Another study shows, the longer duration of exclusive breast feeding was associated with the shorter length of hospital stay and oxygen-use ${ }^{16}$. Breast feeding for less than one month increased the incidence of respiratory syncytial virus-associated infection.

This study of hospitalized bronchiolitis children showed that there is significant correlation between RSV status and non exclusive breast feed children like other study done at home and abroad.

\section{LIMITATIONS}

There are several limitations of our study. First, as it is a small sample size study so actual population parameter may not be represented. Second, it is a single centre study so actual overall scenario could not be concluded from this study. Third due to absence of long term follow up problems could not be characterized adequately. Lastly, due to lack of logistic support all type of evaluation could not be done.

\section{CONCLUSION}

Bronchiolitis is a common respiratory viral illness. Most commonly associated with Respiratory Syncytial Virus (RSV). It is seen that the babies who are exclusively breast feed suffer less likely from bronchiolitis. Breast milk plays a protective role against Respiratory Syncytial Viral (RSV) bronchiolitis. Present study revealed children who were exclusively breast feed had less chance to be infected with Respiratory Syncytial Viral (RSV) bronchiolitis than non-exclusive breast feed infants. So these studies further justify the role that there is no compromise in exclusive breast feeding.

\section{RECOMMENDATIONS}

A study with multicenter large sample needed tobe done to find out the national scenario.

\section{DISCLOSURE}

All the authors declared no competing interest. 
REFERENCES

1. Kabir LARM, Amin RM. Bronchiolitis: An Update. Bangladesh J Child Health. 2002; 26:3-8.

2. Glezen WP, Taber LH, Frank AL, Kasel JA. Risk of primary infection and reinfection with respiratory syncytial virus. Am J DisChild. 1986; 140(6):543-546.

3. Deshpande SA, Northern V. The clinical and health economic burden of Respiratory syncytial virus disease among children under 2 years of age in a defined geographical area. Arch Dis Child. 2003; 88(12):1065-1069.

4. SD Scotland. Number of hospital discharges with bronchiolitis in children 0-24 months in Scotland for the years ending December 2001 2003. [Statistical data]. Edinburgh: ISD Scotland. 2006.

5. Carbonell-Estrany X, Quero J, IRIS Study Group. Hospitalization rates for respiratory syncitial virus infection in premature infants born during two consecutive seasons. Paediatric Infect Dis J. 2001; 20(9):874-879.

6. Heikkinen T, Valkonen H, Lehtonen L, Vainionpaa R, Ruuskanen O. Hospital admission of high risk infants for respiratory syncytial virus infection: Implications for palivizumab prophylaxis. Arch Dis Child Fetal Neonatal Ed. 2005;90(1):F64-68.

7. Sommer C, Resch B Eric A.F. Risk factors for severe respiratory syncytial virus lower respiratory tract infection. The Open Microbiology Journal. 2011; 5:144-154

8. Simos EA. Environmental and demographic risk factors for Respiratory Syncytial Virus Lower Tract disease. J Paediatrics. 2003; 143: 118-126.

9. Papree M. F. Risk factors of Bronchiolitis in young children (2-24 months) Bangladesh Paediatric Pulmonary Forum. 2015; 30-31.

10. Resch B, Manzomi P, Lanari M. Severe Respiratory Syncytial Virus (RSV) infection in infants with neuromuscular diseases and immunodeficiency syndromes. Pediatric Respir Rev. 2009; 10:148-153.

11. Betran AP, De Onis M, Lauer JA, Villar J. Ecological study of effect of breastfeeding on infant mortality in Latin America. BMJ. 2001; 323:303-306.

12. Oddy WH Sly PD, De Klerk NH, Landau LI, Kendall GE, Holt PG et al. Breastfeeding and respiratory morbidity in infancy: A birth cohort study. Arch Dis Child. 2003; 88:224-228.

13. Victora CG, Smith PG, Vaughan JP, Nobre LC, Lombardi C, Teixeira AM et al. Evidence for protection by breast feeding against infant deaths from infectious diseases in Brazil. Lancet. 1987; 2:319-322.

14. Victora CG, Breast feeding, morbidity and mortality. In: Chandra RK, editor. Proceeding of the conference on Nutrition and Immunology St. John's, Newfoundland Biomedical Publishers and Distributors. 1992; 63-72.

15. Bachrach VRG, Shwarz E, Bachrach LR. Breastfeeding and the risk of hospitalization for respiratory disease in infancy. A meta-analysis. Arch Pediatric Adolesc Med. 2003; 157:237-243.

16. Christina T.L. Dornells, Jefferson P. Piva, and Paulo J.C. Marostica Nutritional Status, Breast feeding and Evolution of Infants with Acute Viral Bronchiolitis. J Health PopulNutr. 2007; 25(3):336-343. 